\title{
Practitioner research made easier: A report on the GRIP project
}

\author{
Liz Beddoe, Deborah Yates, Christa Fouché and Phil Harington
}

Liz Beddoe, Christa Fouché and Phil Harington are members of the School of Counselling, Human Services and Social Work at the University of Auckland. Deborah Yates is a clinical social worker and was the GRIP Programme Manager.

\section{Abstract}

An article in this journal in 2007 outlined an innovative programme in progress in Auckland at that time. Growing Research in Practice (GRIP) involved groups of social service practitioners who carried out small and manageable research projects on topics that piqued their interest within the workplace. The main aim of the GRIP programme was to nurture a culture of practitioner enquiry in social service agencies in Auckland, in an attempt at facilitating meaningful change and service improvement in the longer term. This article reports on the findings from the second phase of the evaluation of the programme where seven participants were interviewed about their reflections on GRIP and the outcomes of the programme. The article offers recommendations for social service practitioners in this regard.

\section{Background}

The Growing Research in Practice initiative (GRIP, as it is commonly known) was a programme of supported practitioner research in Auckland, which grew out of meetings held with practitioners and managers at Massey University in 2004. During these meetings, the complex nature of conducting research in practice was explored. The discussion was furthered through the production of an e-newsletter, Evidence (North), and colleagues from the University of Auckland joined the discussions. It was from this sharing of ideas between academics and practitioners that the concept of GRIP emerged and the project's early stages were reported in 2007 (Beddoe, Fouché, Harington, Light, Lunt \& Yates, 2007). Funding was secured from the Families Commission Innovative Practice fund, the Ministry of Social Development's SPEaR Linkages fund and in partnership with the Aotearoa New Zealand Association of Social Workers from the ASB Trusts. Further funds were later awarded by the University of Auckland to support ongoing enquiry into the GRIP process. A part-time project manager was employed and a practitioner joined what was now the 'GRIP team' as an advisor and 'critical friend' (Kember et al., 1997; Beddoe et al., 2007, p. 44).

A workshop to launch the GRIP initiative was held in February 2006 and attended by a wide range of social service practitioners from across the Auckland Region. Accessed via existing professional networks, they represented non-governmental organisations, District Health Boards, Government Departments and small voluntary groups. On that day they were invited to form small research groups and to put forward brief research proposals on topics of interest. Despite fearing a poor response, the GRIP team was delighted to receive 18 expressions of interest. Of these, nine were chosen as fitting the criteria and representing 
a broad range of practice and cultural perspectives. Each group appointed a liaison member, later referred to as the 'group custodian' (Lunt, Fouché \& Yates, 2008, p.48).

A second workshop in April 2006 brought together these nine groups, on average consisting of four or five practitioners, to welcome them and brief them further on the GRIP programme plan and timelines. (Please note that full information about the projects is available in the Families Commission published report Lunt, Fouché \& Yates, 2008 available on line at http: / / www.nzfamilies.org.nz / sites / default / files / downloads / IP-GRIP.pdf.)

Presentations were made on aspects of getting research underway. Four more workshops over the following 10 months guided the groups through the research process, with a range of research experts presenting at the workshops to enliven and enrich the learning. A collection of these resources, referred to affectionately as 'The Cookbook', was published by the GRIP team, for use as a reference for future research (Fouché, Lunt \& Yates, 2007). Each group was provided mentoring to support the progress of their research project (Fouché \& Lunt, 2010). Participants were consulted throughout about their experience via questionnaires, interviews and using the 'World Café' process (a group process reported in Fouché \& Light, in press; see Brown \& Isaacs, 2005) and this material was used by the GRIP team in their own research.

The practitioners faced many challenges. It was appreciated that social workers work in a dynamic and unpredictable environment, within organisations that are compelled to respond to human circumstances and where research is a very low priority. Staying on track with the research goals, even finding time to meet, was often difficult. Some group leaders were promoted to other jobs or moved to other agencies and one group disbanded as a result of the project no longer being viable. Many of the project group members had no prior experience of research, so felt disadvantaged at times. For some of the practice researchers, English was a second language. They were collecting data in their own language and translating it into English for discussion with the GRIP teams, then back into their own language for their participants and readers.

At the Growing Research in Practice Symposium held in Auckland in April 2007, the practitioner groups were able to present their learning from the year: some were able to present findings, others to assess their progress and report on the impact of the process. This symposium was attended by participants, their colleagues, managers and representatives of project funders and provided an opportunity both for the reporting of results and a celebration of achievements. For the participants in the programme, the symposium was itself a rather distinctive event in the life of the project with the presentation of the journey and project results. A compilation of papers was published as a record of their activities (Yates, 2007). Two groups have taken their research further and gone on to present at conferences and / or publish articles in professional journals (Haultain, Thompson, Loli, Herd \& Comber, 2009; Zhang, Wong, Li, Yeh \& Zhao, 2009).

Members of the GRIP team have also actively sought to disseminate the learning gained in this initiative and GRIP has been presented at conferences and seminars in Australia, Canada, Scotland, the United States and Wales as well as in New Zealand. A full and detailed report on the GRIP project was published by the Families Commission (Lunt, Fouché \& Yates, 2008) and is available on the Commission's website. A great deal of interest in the 
GRIP model has been expressed, particularly internationally. Our first article in Social Work Review discussed findings from data and observations collected towards the end of the GRIP programme (Beddoe et al., 2007). It is now time to report back to the New Zealand professional community on the final stage of the research, carried out since the GRIP programme was completed. This article reports on the more indelible outcome of the project and our analysis of the 'year later' interviews.

\section{Method}

The overarching objective of the GRIP project was to assist the development of a culture of practitioner enquiry in social service agencies in Auckland, with a longer-term commitment to meaningful change and service improvement. Because little was known or understood about the interactions that occur between practitioners, their employers, academics and others involved in such a process, the GRIP team set out to develop a map of what works in facilitating the uptake of research and results amongst social work practitioners in local practice settings. Data collected for this purpose during the GRIP programme included: feedback questionnaires completed at the end of each seminar; consultation with groups during the programme, including a series of qualitative interviews (four with groups and six with individual group custodians); minutes of GRIP team meetings; progress reports written to funders; and the discussions generated in the 'World Café' process (Fouché \& Light, in press; Brown \& Isaacs, 2005). Two sets of interviews were conducted in the study. The first set of interviews provided the GRIP participants the opportunity to give honest feedback on their experience of being involved in the GRIP initiative and describe what worked and what didn't in terms of the provision of training through the seminars and the workplace visits of the mentors. Some of these reflections were incorporated in the report on the GRIP initiative to the Families Commission (Lunt, Fouché, \& Yates, 2008). On completion of the GRIP programme, a second phase of evaluation was undertaken and seven participants were interviewed about their reflections on GRIP and the outcomes of the programme for them and their teams. The critical friend was also interviewed as she had experienced GRIP as a practitioner-researcher and worked alongside the other participants. It is a discussion of these findings that is the focus of this article.

\section{The motivation for this initiative}

The relationship between social work practice and research has been the subject of debate for several decades (McDonald, 2008) and has gone hand-in-hand with the struggle for the recognition of social work as a profession. The GRIP team expected to encounter many challenges as the literature provided many examples of the tension between research and practice. These tensions are significant, both in the public domain and within the universities, where social work academics face challenges from the competing demands of teaching, maintaining relationships with the field, and research and publication (Green, 2006; Orme \& Powell, 2008). Regulation and professional bodies require social workers to have an understanding of research and in New Zealand, as in many countries, there is an expectation that social work educators encourage social workers to become research-minded. Generally social work preparatory education includes the requirement that graduates are able to locate, read and learn from research and to update their knowledge beyond graduation. It is commonly understood though that social workers struggle to achieve these goals in the busy world of practice. 
The evidence-based practice movement is also in response to 'demands for better quality standards and outcomes and greater professional accountability in health and social care' (McCrystal \& Wilson, 2009, p.2) and an expectation that clients have a right to services that can be shown to be effective. While social agencies have responded with a range of mechanisms, including increasingly detailed documentation of service activities and mechanisms to ensure compliance with policy, 'This demand for accountability ... necessitates understanding what really happens to clients as a result of the services provided' (Wade \& Neumann, 2007, p. 50). Research-minded social workers and their agencies should model and update practice and policy by staying abreast of the most recent research evidence, (Trinder, 2000; Newman, Moseley, Tierney \& Ellis, 2005; MacDonald, 2008; McCrystal \& Wilson, 2009).

While the 'Evidence-based Practice (EBP)' movement in social services is contentious (Orme, 2000; Trinder \& Reynolds, 2000; Sheldon, 2001; Webb, 2001) it has nevertheless promoted the notion that social work practice be informed and developed from the results of scientifically conducted research. Problematically, however, there is a gulf between the worlds of researchers and academics (producers) and frontline practitioners (consumers). Rarely is the information or research produced locally, rather it is supplied through knowledge management processes. Yunong and Fengzhi $(2009$, p. 178) note that the availability of evidence relevant to the social work practitioners is frequently problematic simply because they often lack access to published research. Rather they receive the distilled evidence filtered through internal training as, especially in large government bureaucracies, knowledge is 'managed' centrally and dispersed to the frontline through programmes and processes. As McNeil has asserted, the 'image of social workers as "information processors" connotes a mechanistic approach that is untenable for most practitioners' (McNeil, 2006, p. 148). Social workers' training, ethics and inclinations tend towards critical scrutiny of new programmes delivered to the frontline by 'management'. Kincheloe and McLaren emphasised that managerial perspectives characterise workers 'as rationalistic problem solvers who apply scientifically tested procedures to workplace situations ... in the modernist workplace hierarchy, managers start with research provided by experts and train workers in accordance with such findings' (Kincheloe \& McLaren, 1994, p.150). Organisations filter which evidence is deemed best for application and this currently favours evaluative research to support intervention programme choices. For social workers such choices can never be considered uncritically.

\section{Practice-based research}

Evidence-based practice has thus not translated easily to the social work environment, where variables relating to culture and belief, relationship and social experience may be seen to belie measurement (McCrystal \& Wilson, 2009) and the top down approach to utilisation has tended to marginalise practitioner involvement. While in the United Kingdom, authors Newman et al defend the ongoing use of the term EBP on the grounds that it is universally accepted as a mark of professionalism, they admit that:

... rightly or wrongly, it (EBP) has become associated with approaches which elevate empirical and quantitative sources of knowledge to a pinnacle of authority, diminish the value of practitioner experience, intuition and insight, underestimate the complexity of human affairs and fail to acknowledge the importance of context and process (Newman et al., 2005 p. xiii to xiv).

McCoyd, Johnson, Munch \& LaSala (2009) have gone so far as to develop the term 'quantocentrism' to describe quantitative research involving large data sets and complex 
statistical extrapolation of results. They fear that quantocentrism is seen as 'the gold standard of knowledge generation' to the detriment of the collecting of 'process oriented and experiential data' more suited to social work (McCoyd et al, 2009, p.6) They also believe that quantocentric research is off-putting to social work students and practitioners alike, who find it rarely relates to their placement or practice experience or environments.

The literature suggests that the drive for greater research activity has been constantly frustrated by the disinclination of social workers to take the avid interest in research required for this to work and one study by Rosen et al in 1995 found only one per cent of practice to be based on the use of research; practitioners rather favour conceptually based interventions. Furthermore, social workers who do want to research may find 'agency culture and infrastructure ... still grounded in the assumption that knowledge is generally stable' and are therefore resistant to committing to ongoing knowledge generation (Mullen, Bellamy, Bledsoe, \& Francois, 2007, p.575). As Humphries (2008, p.186) points out, evaluation tends to focus on individual behavioural change, but need not exclude consideration of environmental and social conditions. Social workers' person-in-environment approach may disincline them to focus on individual change.

Considering the constantly changing social and political landscape within which social work operates, it certainly seems necessary for social workers to be aware of research findings and to maintain an interest in updating their knowledge and sense of enquiry into them. Examining one's own practice, its basis and effectiveness and learning about and understanding the client groups, their cultural and historic contexts, the local environment and the systems which operate and impact on it could appear to hold more relevance and 'reality' for social workers, and to most reliably inform their practice. Using more 'local' methodologies, suited to the nature of social work, notably qualitative interviews and focus groups, but also less familiar methods, such as data mining, might also make 'more sense' at a practice level.

The GRIP initiative aimed to achieve greater integration of research activity and everyday practice. While the development of greater research-mindedness in social work can be seen as something akin to a culture shift in various sites of practice, the GRIP study was motivated more by the need to establish research innovation as a feature of social work practice than an intention to position social work as a form of social accountancy! The GRIP team wanted to inspire that sense of inquiry that could enable social workers to explore issues, to improve their knowledge, eschew anecdotal accounts in favour of some presentation of accurate description, identifying patterns using various criteria and developing the sort of data and theory that could be of value to practitioners and students alike.

Practice-oriented research may be carried out by individuals steeped in research skills - be they practitioners, academics, postgraduate students or professional researchers working in conjunction with social service agencies. Even as subjects of research social workers should be able to operate as informed participants, critically able to shape research and actively engaged in a concern for evidence-led appraisal of populations, interventions, resource and process.

Epstein first used the term practice-based research (PBR) in relation to social work in the 1990 s, as aiming to inspire practitioners to consider research to enhance their own practice 
decision making (Epstein, 2002). PBR is distinctive in recognising the grounding of such research in the world of practice and its demands. For Epstein, the many practice-based studies he has been involved in have 'never placed research priorities above practice priorities' (Epstein, 2009, p.218). Such research can contribute to knowledge creation but remains firmly grounded in practice improvement. With this in mind, Ground water-Smith points out, PBR might most readily align itself with action research, so named by Lewin in the 1960s, which is motivated by self-analysis, curiosity and social justice, and involves enquiry to inform social action by those parties most closely involved with the research focus (Groundwater-Smith, 2007). Groundwater-Smith (2007, p.3) sees PBR as having developed from the action research tradition in that it is research carried out by professionals to inform practice. She contends that PBR 'is praiseworthy on the grounds that it has a greater potential for impacting on the relevant field than much of what might count as traditional research'.

Groundwater-Smith, citing Stenhouse, does not minimise the risks attached to such an approach, acknowledging that it can be seen to lead to 'heresy', by challenging 'embedded and enduring (institutional) practices' (Groundwater-Smith, 2007, p.2). In addition, staff undertaking research projects can be seen as being less productive as a result, or less focused on the job at hand (Wade \& Neuman, 2007, p.50). Wade and Neuman also suggest that social work attitudes to research and researchers might be marred by past agency practices where administrators have utilised research findings to punish poor practice and practitioner associations with research as a stressor based on previous academic exposure 'which may perpetuate anxiety and resistance toward research-related activities' (Wade \& Neuman, 2007, p. 50). Groundwater-Smith considers that the engagement of a range of professionals from within the field, working cooperatively to learn and to solve problems reflectively on a small scale but systematic approach, helps to both reduce resistance to research and transform practice. GRIP, with its overall goal to develop a model of partnership between educators, social workers and their employers to enhance research activity and research mindedness, fits this paradigm.

But despite willingness and curiosity (Joubert, 2006), perhaps the main deterrent for most social work practitioners is the issue of finding time, whether to read about the research of others or to learn about and actually carry out research themselves, when struggling with large caseloads and the demands of emergency work (Yunong \& Fengzhi, 2009). This was certainly the most pressing issue for GRIP participants. A major focus in developing the actual GRIP process was on tackling the issue of managing time and work pressures. This was done through working in groups, sharing the work, meeting regularly, providing regular mentoring, and keeping the research both small and short term.

The GRIP team was keen to ascertain participants' views about the effectiveness of these aspects of the initiative in reducing some of the barriers to social worker involvement in practice-based research. As discussed in the methodology, the views of a small selection of GRIP participants about the GRIP experience and outcomes were explored at the completion of the initiative. The following discussion summarises reflections from these interviews carried out in late 2007-early 2008. Seven people were interviewed in this second round of interviews. Most were participants in the research groups, although the critical friend was also included as she had experienced GRIP as a practitioner-researcher and worked alongside the other participants. 


\section{Findings}

It was clear from the initial evaluation (Lunt, Fouché, \& Yates, 2008), that the overall experience for GRIP participants was positive. While there were many difficulties in terms of finding the time to work together and of maintaining motivation and focus in the face of so many other professional demands, agency restraints and restructurings, unevenness of research experience and language and cultural differences, the large majority of participants enjoyed being part of GRIP, learning a great deal and developing confidence in using research skills. Most reported much increased enthusiasm for using research in the workplace.

In the subsequent phase of the enquiry about the GRIP experience, a series of qualitative interviews were conducted in 2008, with the six group custodians who were available for interview and the 'critical friend'. The purpose of these interviews was to record the participants' reflections on the GRIP programme since its completion to explore whether there was any ongoing impact and development, both professionally and in terms of organisational culture. Ethical approval for the interviews had been gained from the University of Auckland Human Participants Ethics committee. The seven semi-structured interviews were audio-taped, transcribed and then coded using thematic coding. Table 1 sets out the themes that guided the interviews.

Table 1. Themes of inquiry.

\section{Themes of inquiry}

1. Explore respondents' reflections on being in GRIP:

a. during the project period/year

b. since the symposium and completion of the research.

2. Explore the impact of participation on professional identity.

3. Explore the diffusion of learning into the professional community that came from their work.

a. Was there a conference paper/publication?

b. Have others asked about the experience and expressed an interest in such activity?

4. Consequences for the practitioners and other staff in the agency.

a. How did the project influence the agency:

i. as an undertaking and

ii. for the results it produced?

b. What was the role and response of management to the project participation?

5. Where does the respondent want to go next with practice research?

\section{The GRIP experience}

Participants were asked to once again comment on the GRIP experience, with the benefit of hindsight, and as in the first interviews, this was overwhelmingly positive.

One participant expressed great enthusiasm about the entire GRIP process, stating: 'it's just been an absolute privilege to be part of the whole process personally and profession- 
ally'. There seems to be a number of reasons for such positive feedback, expressed across the range of participants.

Receiving support from the universities without being required to be enrolled in a tertiary course was especially appreciated and was seen as 'a very easy opening for social workers to walk through, to begin to start a research career really.' Another stated:

I've always had an interest in research and done a certain amount so to see GRIP was exciting for me, oh great something we can do in practice and the university coined it and it is practice based. I don't have to go off to university to do this and we can actually implement it in our programme and it can be about what we are actually doing day-to-day. I had my ears and eyes open for that kind of opportunity. When I saw it, I went for it and I think it's a great model.

The experience of researching with a group of colleagues, some known and others newly met was a major benefit:

It was the whole process of coming together and working on it together ... the sense that you can bring totally diverse groups and representatives of diverse groups together and actually achieve something.

Another felt the diverse group that had formed was beneficial and made a:

... solid bond... I have made some friendships with those other social workers, that are deepened because of that piece of work, and I treasure that .We' $\mathrm{d}$ be ready to work (together) again in a heartbeat.

A group that had run a programme together for a long time also felt their relationships had been strengthened through the focus on the research and the time spent together. The sharing of the research workload was also acknowledged as advantageous, 'as constantly advocated by the GRIP team'.

There was clearly concern about the lack of reflection in social work and the opportunity that GRIP offered to examine one's practice in detail with colleagues was considered a rare one. Said one participant:

The danger is that we just do stuff and we never really look at it and don't even evaluate the outcomes about what we do in (our) work and that's where research comes into it'.

Another valued being able to do this in safety:

It was very practice focused, researching our practice and talking about our practice, in a very non-threatening and safe environment'.

There was amazement at the absolute relevance and applicability of the findings:

...we can actually implement it in our programme and it can be about what we are actually doing day-to-day.

GRIP also enabled at least one group to examine aspects of their own culture/s: 'It enabled us to kind of put something under a spotlight if you like and just have a look at it.' This 
group started meeting on a regular basis during GRIP and were still doing so at the time of these interviews for the same purpose.

One group worked cross-culturally, one participant stating: 'Certainly GRIP ... informed my research practice around the different cultural ... perspectives.' This mixed group shared experiences of cultural models around one aspect of social work, this being made more possible because the group leader had done 'a lot of work around creating a safe environment for us to talk and share experiences.'

The GRIP experience also engendered a tremendous sense of pride and satisfaction, at different stages of the research: 'After the first sort of analysis of the data, I think people felt really good about it.' And on presenting at the Symposium: 'there was real pride that "Hey we've done really well!". There was quite a sense of ownership to the project.' Another participant commented:

There was also a new-found respect for research and all that is involved in it.

It made you realise that there's a lot that goes in behind the scenes before something comes out the other end. ... I think all of us came away with huge respect for research and what's needed to really get good research and the time factor ... and that thing about staying committed to the outcome, that you were going to follow it through to an outcome.

\section{Time management}

As noted earlier, there are many obstacles to undertaking practice-based research but perhaps the main deterrent for most social service practitioners is the issue of managing time, whether to read about the research of others or to learn about and actually carry out research themselves, when struggling with large caseloads and the demands of emergency work. Tackling the issue of managing time and work pressures was in fact a major focus in developing the actual GRIP process and strategies included keeping the research both small and short term, working in groups and sharing the work, meeting regularly and providing regular mentoring. The majority of participants cited time management as a major concern throughout the project (Lunt et al., 2008, p. 39) mentioning acute client demands, shift work and variable ability to manage time independently as contributing factors.

The 'post GRIP' interviews confirmed that for busy practitioners, time was the main and most prominent difficulty in achieving their aims as practice researchers. While one participant politely described it as a 'concertinaed timeframe ... it was a lot of work, a lot of activity and a lot of discovery in a very short period of time' one or two others spoke of 'the logistics' and stress in trying to manage a busy caseload, including emergencies, while simultaneously doing research. One participant felt there was work left incomplete because of time constraints:

I guess part of the frustration around GRIP was the fact that we're constantly pressured to do clinical work, and of course there wasn't all the time that we would have liked to really reflect on the data, and do a kind of textural analysis.

While working as a group helped minimise the workload for individuals, at times the most enthusiastic and energetic found themselves doing the lion's share of the work. Lack of time 
also impacted on the level of data analysis done. Having the support of management helped. 'The agency - the professional leaders and the senior management - were supportive, very supportive of it.' Rather than the demand on employees' time alienating management, it was seen by one participant as having been a really important first step into research by the agency.

\section{The effect on practice}

While the experience for the GRIP participants was mainly enlightening but also at times frustrating, the effectiveness of the project is more difficult to evaluate. Did GRIP achieve its broader goals? Did the GRIP groups' findings have an impact on practice? Did the project have a lasting impact on the individuals and agencies involved?

Participants spoke of how they and their group had learnt a great deal about their own practice. Two groups had, as part of their research design, brought together focus groups of practitioners and client families to reflect on and discuss an aspect of social practice and one had involved 40 people. This had given the social workers involved a precious opportunity to reflect, listen and discuss and was seen as hugely beneficial to them and their practice.

Another group found that enquiring into the effectiveness of the programme they were running not only allowed them to make improvements but also increased their confidence in their work enormously. They had built evaluation into their ongoing work, ensuring that all future client activities were monitored in this way.

Other groups had embarked on further stages or ongoing research and the learning was continuing. One agency had since held a large number of focus groups across a broad urban area and was collating their results. Another group leader saw their research as ' a foundation upon which we can now build which was always what it was designed to be' and another was always on the lookout for an opportunity to further their group's research.

\section{Dissemination}

Several groups had presented their findings and/or GRIP experience at conferences, both 'around the country in various different events' and overseas, and within the workplace, and dissemination was an ongoing project.

This was not without considerable effort, as so many other demands stood in the way. 'It's that whole issue around ... as soon as the deadline's over, you know, other things take over.' For some, writing up the findings for publication was, at the time of the interview, a daunting prospect and other plans, such as setting up regular reflective practitioner groups, were on the back burner. However, since these interviews were conducted, two articles were accepted for publication (Zhang et al., 2009; Haultain et al., 2009).

Notably for one participant the overall gains were about connectedness, not just public recognition:

... the presentation and the working together was more significant than the publication of an article ... it was about the connecting, it was about connecting as a group that was most important. And the sharing of practice, and each one of us, we learned from each other, regardless of 
whether, the message that we passed to the outside world, or to other professions, we learnt a great deal from each other.

\section{The impact on career development}

For group members, according to one group leader, participation in GRIP had given them 'a sense of self-confidence and validation which they didn't have prior ... and quite a few of them now are studying tertiary social work', implying that this has been directly influenced by their participation in GRIP.

One or two of those interviewed had been using skills learned in GRIP in their own academic study. One stated 'GRIP gave me some real clues how to go about (the research I'm doing). It also linked me up with some of the academics (who) have assisted me ever since.' These post-GRIP mentoring relationships continue today between the GRIP team academics and several GRIP participants

One proactive group leader reflected that her career had been greatly helped, both with subsequent tertiary study and in the experience of presenting at a conference for indigenous researchers overseas. 'I was exposed to a lot more opportunities as a result of the research.' There had been a tremendous sense of pride also in presenting the only piece of practitioner research at the conference, amongst so many academic ones. Members of her audience seemed excited by this, as if they 'never thought (practitioner research) would be happening yet'.

One group, which had evaluated their use of an American programme with a specific client group, had by now presented their findings overseas. They reported that this had created a lot of interest and some good connections with practitioners working in the same field and using the same programme. Some of these people had gone on to use the evaluation model to assess and adapt their use of the programme. This is an excellent example of a bottom-up approach to evaluating and adapting to local conditions and populations a programme that was developed for general use in the United States.

One project involved service users from the beginning. As Berger (2010, p.180) has noted often, research findings will lack clear guidance on practice implications, but when they 'are offered, they tend to be conceptualised in general, rather than in clear applicable terms. For example, practitioners are advised to be aware, reflective and culturally-competent without being guided as to how to gain such competence'. In this project, members of the Chinese agency community, staff and consumers were immediately able to implement learning in practice in an adapted mental health programme (Zhang et al., 2009). The long gap between knowledge production and knowledge use was reduced to a minimum.

\section{The impact on agencies, colleagues and clients}

In the agency mentioned above, the research and evaluation carried out as a result of GRIP was proving extremely useful in applying for funding, so that they were able to expand their programme over a wider geographical area. Within the agency, members, including clients, had increased their interest and confidence in the work and had become 'more active and involved in the programme'. This was providing the support necessary for expansion. The advantages to their client group of ongoing evaluation were also tremendous, as per Newman et al's statement: ‘a knowledgeable client is an empowered client' (Newman et al., 2005, p.xv). 
Much of this was also true for a medium-sized agency:

... we use it (our research findings) as part of our induction package for new workers coming here as a resource as well as for our own funding applications and the likes of that to demonstrate that we do critique ourselves and we are taking a close look at how we could improve the way we deliver our services.

In larger agencies professional leaders and managers were keen, as a result of GRIP, to maintain a research base and develop a more research-minded social work staff.

We're starting to talk about how we could get some learning groups up and running in the (agency), that are kind of reflective practice groups. Or, you know, just even little things like audits. So it's like we've got to back up the truck a little bit ... if we were able to appeal to a wider range of practitioners.

One interviewee with a more senior role stated:

I liaise with level four, level three managers. And so the profile of social workers who do research has been heightened. Because I get them up to speed, by just mentioning the word GRIP and I think GRIP, the word, has come out at various forums where it's associated with social workers. So there has been a connection there.

\section{Continuing the GRIP legacy}

While the GRIP initiative has become something of a marker of how to support social worker research in practice, it was no small matter for academics to obtain the funding necessary to make GRIP happen, even pre-recession, and there seems little chance of it becoming an ongoing or regular project. However, with indicators of the impact of GRIP within agencies and upon the careers of individual participants, and the ongoing enthusiasm of GRIP team members, it seems there may be a viable seedling from which to continue to grow research within agencies.

The need to ensure that agency management personnel understand, value and promote in-house research is recognised as vital to practice-based research getting traction. Lack of this had been seen earlier by some groups as a weakness in their process. It is stated that:

Management has to agree to it and totally support it and I think management will do that only on a cost-benefit analysis-type thing and ... some sort of belief that research is of value to the organisation.

This same person felt that the GRIP approach might be seen as an example of how research could be affordable:

It's a possible and cheaper way of doing research than any other way and it actually has an impact on the organisation. So I think a lot of research may happen (as a result of GRIP).

There is also recognition of the potential that GRIP has created in enhancing agencies' relationships with the universities:

You know, we are starting to negotiate much more (as in) 'What does this partnership look like? What's its potential?' And I definitely think that's because of our ... extended contact over GRIP ... 
One person sees it as the responsibility of practitioners:

There should be literally a paradigm or cultural shift, where it should be the practitioners who take the initiative to lead the research. Just like mental health consumers actually provide the ground swell for the consumer movement, so should the ripples from GRIP maybe influence practitioners to take (up) research. So therefore research comes from the bottom up, because we're the ones who actually have the closest contact with our population.

However, there is also a strong sense of frustration expressed in the belief that only a very small percentage of social workers in the workplace are interested in research. These are described as:

A group of practitioners that are already, you know, they read, they think about what they're doing, they go to training - it's that top $5 \%$.

It was also thought there was resistance at the time of GRIP from some colleagues:

My overwhelming experience is that it's not particularly welcome by a lot of people. It's just so ... out of left field.

The dilemma with time is also noted:

Nobody wants to do it because they know that it means more work. They like seeing other people doing it though.

One person noted that negotiations within their agency to date had 'probably been from the passion base of individuals really' and another had been reflecting on how this could be widened. 'I suppose (I'm) thinking about how ... a process, a GRIP-type process, could be a bit more inclusive of a wider audience. That's what I'm ... struggling with now really.'

Although this issue remains unsolved, is it possible that this $5 \%$ of motivated and passionate social workers could lead a paradigm shift as outlined above? Is this how Groundwater-Smith's cooperative partnership, one that solves problems reflectively and on a small experimental scale and involves a range of professionals within a practice environment, could be realised (Groundwater-Smith, 2007)?

\section{Conclusion}

The findings from this evaluation included, over and above the reflections on the GRIP experience, issues related to time management; impact on practice; dissemination, impact on the agencies; and impact on career development. The core message across these themes is that the partnership model of supporting research activity in practice worked. It was well-received by all involved and produced benefits in terms of the results of the practice projects, but more than that, also had huge unintended benefits. However, it seems that there are a number of challenges that may prevent a repeat of this successful venture. The lack of leadership within agencies for practitioner research and the need to get managers on board more (confirming Joubert's comments on the importance of managerial support (Joubert, 2006, p156.) seem to be the major challenge. Mitchell, Shaw and Lunt (2008, p. 25) also ask the important question 'Is practitioner research best left as a bottom-up development or 
does it require strategic direction?'. The initiative for this partnership came from universities - against many odds. The responsibility to take learning from this project forward for the benefit of social work practice rests with the leadership of social service agencies.

Acknowledgements. The authors acknowledge funding provided by the University of Auckland Faculty of Education Research Development Fund and The University of Auckland Staff Research Fund for the second phase evaluation of the GRIP initiative.

\section{References}

Beddoe, L., Fouché, C., Harington, P., Light, G., Lunt, N., \& Yates, D. (2007). Growing research in practice: The story so far. Social Work Review, 19(1), 39-50.

Berger, R. (2010). EBP: Practitioners in search of evidence. Journal of Social Work, 10(2), 175-191.

Brown, J., \& Isaacs, D. (2005). The World Café: Shaping our futures through conversations that matter. San Francisco: Berrett-Koehler.

Epstein, I. (2002). Using available clinical information in practice-based research: Mining for silver while dreaming of gold. Social Work in Health Care, 33(3-4), 15-32.

Epstein, I. (2009). Promoting harmony where there is commonly conflict: Evidence-informed practice as an integrative strategy. Social Work in Health Care, 48(3), 216-231.

Fouché, C. \& Light, G. (in press).An invitation to dialogue: The World Café in social work research. Qualitative Social Work.

Fouché, C., \& Lunt, N. (2009). Using groups to advance social work practice-based research. Social Work with Groups, 32(1), 47-63.

Fouché, C., \& Lunt, N. (2010). Nested mentoring relationships: Reflections on a practice project for mentoring research capacity amongst social work practitioners. Journal of Social Work. Published online August 2, 2010, doi: $10.1177 / 1468017310378780$

Fouché, C., Lunt, N., \& Yates, D. (2007). Growing research in practice: A collection of resources. Auckland: Massey University. Accessed 7 August 2010 at: http:/ / www.education.auckland.ac.nz/uoa/grip-publications

Green, L. C. (2006). Pariah profession, debased discipline? An analysis of social work's low academic status and the possibilities for change. Social Work Education, 25(3), 245-264.

Groundwater-Smith, S. (2007). In praise of practice: What we can learn from practice based research constructed as ethical enquiry. Paper presented at the Growing Research in Practice Symposium. Auckland.

Haultain, L., Thompson, A., Loli, M., Herd, J., \& Comber, S. (2009). Whanau meetings in the hospital: Uncovering the unique role of social workers. Aotearoa New Zealand Social Work, 21(4), 4-14.

Humphries, B. (2008). Social work research for social justice. Basingstoke: Palgrave Macmillan.

Joubert, L. (2006). Academic-practice partnerships in practice research: A cultural shift for health social workers. Social Work in Health Care, 43(2/3), 151-162.

Kember, D., Ha, T.-S., Lam, B.-H., Lee, A., NG, S., Yan, L. et al. (1997). The diverse role of the critical friend in supporting educational action research projects. Educational Action Research, 5(3), 463-481.

Kincheloe, J. L., \& McLaren, P. L. (1994). Rethinking critical theory research. In N. K. Denzin \& Y.S. Lincoln (Eds.), Handbook of Qualitative Research (pp.138-157). Thousand Oaks: Sage.

Lunt, N., \& Fouché, C. (2009). Action research for developing social workers' research capacity. Educational Action Research, 17(2), 225-237.

Lunt, N, Fouché, C \& Yates, D. (2008). Growing research in practice: An innovative partnership model. Wellington: NZ Families Commission. Accessed 7 August 2010 at http: / / www.nzfamilies.org.nz/sites/default / files / downloads/IP-GRIP.pdf

McCoyd, J. L. M., Johnson, Y. M., Munch, S., \& LaSala, M. (2009). Quantocentric culture: Ramifications for social work education. Social Work Education: The International Journal, 28(8), 811-827.

McCrystal, P., \& Wilson, G. (2009). Research training and professional social work education: Developing researchminded practice. Social Work Education: The International Journal, 28(8), 856-872.

MacDonald, G. (2008). Social work in the UK: A testing ground for trialists. Journal of Children's Services, 3(1), 27-39.

Mitchell, F., Shaw, I. F., \& Lunt, N. (2008). Practitioner research in social services: A literature review, Report prepared for The Institute for Research and Innovation in the Social Services. York: University of York.

Mullen, E. J., Bellamy, J. L., Bledsoe, S. E., \& Francois, J. J. (2007). Teaching evidence-based practice. Research on Social Work Practice, 17(5), 574-582.

Murphy, A., \& McDonald, J. (2004). Power, status and marginalisation: Rural social workers and evidence-based practice in multidisciplinary teams. Australian Social Work, 57(2), 127-136.

Newman, T., Moseley, A., Tierney, S., \& Ellis, A. (2005). Evidence-based social work: A guide for the perplexed. Lyme Regis: Russell House Publishing.

Orme, J. (2000). Social work: 'the appliance of social science' - a cautionary tale. Social Work Education: The International Journal, 19(4), 323-334. 
Orme, J., \& Powell, J. (2008). Building research capacity in social work: Process and issues. British Journal of Social Work, 38(5), 988-1008.

Rosen, A., Proctor, E. E., Morrow-Howell, N., \& Staudt, M. (1995). Rationales for practice decisions: Variations in knowledge use by decision task and social work service. Research on Social Work Practice, 5(4), 501-523.

Sheldon, B. (2001). The validity of evidence-based practice in social work - a reply to Stephen Webb. British Journal of Social Work, 31(5), 801-809.

Stahl, R., \& Shdaimah, C. (2008). Collaboration between community advocates and academic researchers: Scientific advocacy or political research? British Journal of Social Work, 38(8), 1610-1629.

Trinder, L. (2000).Evidence-based practice in social work and probation, in L. Trinder \& S. Reynolds (Eds.) Evidencebased practice: A critical appraisal (pp.138-162). Oxford: Blackwell.

Trinder, L. \& Reynolds, S. (Eds.). (2000). Evidence-based practice: A critical appraisal. Oxford: Blackwell.

Wade, K., \& Neuman, K. (2007). Practice-based research: Changing the professional culture and language of social work. Social Work in Health Care, 44(4), 49-62.

Webb, S. A. (2001). Some considerations on the validity of evidence-based practice in social work. British Journal of Social Work, 31(1), 57-79.

Yates, D. (Ed.). (2007). Growing research in practice - a collection of papers. Auckland: Massey University. Available on 7August 2010 at: http:/ / www.education.auckland.ac.nz/uoa/grip-publications

Yunong, H., \& Fengzhi, M. (2009). A reflection on reasons, preconditions, and effects of implementing evidencebased practice in social work. Social Work, 54(2), 177.

Zhang, W., Wong, S. Y., Li, Y., Yeh, H.-S., \& Zhao, Y. (2009). The Wellness Recovery Action Plan: Effectiveness with Chinese consumers. Aotearoa New Zealand Social Work, 21(4), 94-102. 